\title{
MEMÓRIAS, SABERES E SONHOS NA FORMAÇÃO CONTINUADA DE PROFESSORAS DO CAMPO
}

\author{
Simone da Silva Ribeiro ${ }^{1}$ \\ Darieli Daltrozo Ilha ${ }^{2}$ \\ Luciana Pacheco Marques ${ }^{3}$
}

\begin{abstract}
RESUMO: Este texto traz reflexões e questões a partir de uma proposta de pesquisa colaborativa na qual as narrativas autobiográficas de professoras do campo nos apresentam elementos sobre a docência, seja na forma como a exercemos seja como a descrevemos através das lembranças da infância e da escola. Assim, com foco nas histórias de vida destas docentes, atentamos para as tessituras possíveis na construção de conhecimentos neste contexto, cujo cenário é a Escola Municipal de Santa Bárbara, localizada no município de Miradouro/MG. Trazemos, para dialogar conosco, autores como Paulo Freire, Michel de Certeau e Boaventura de Sousa Santos que se entrelaçam às falas recheadas de memórias, saberes e sonhos das professoras.
\end{abstract}

Palavras-chave: Memórias - Construção de Conhecimentos - Formação Docente.

\footnotetext{
${ }^{1}$ Doutora em Educação pela Universidade Federal de Juiz de Fora, Mestre em Educação pela Universidade do Estado do Rio de Janeiro e Licenciada em Pedagogia. Atua como docente nas séries iniciais do Ensino Fundamental no Colégio de Aplicação João XXIII da Universidade Federal de Juiz de Fora, onde coordena o Grupo de Pesquisa Educação, Culturas e Sustentabilidade, desenvolvendo projetos de pesquisa e extensão nos seguintes temas: educação e territorialidade, conhecimentos tradicionais, currículo e cotidiano escolar. E-mail:simonerib@gmail.com

${ }^{2}$ Mestranda em Educação pela Universidade Federal de Juiz de Fora; especialista em Gestão Escolar pela Universidade Castelo Branco e em Mídias na Educação pela Universidade Federal de Santa Maria; Licenciada em Pedagogia pela Universidade Estadual do Rio Grande do Sul. E-mail: darieli.ilha@gmail.com

${ }^{3}$ Doutora em Educação pela Universidade Estadual de Campinas; Mestre em Educação pela Pontifícia Universidade Católica do Rio de Janeiro; Especialista em Psicopedagogia pelo Centro de Ensino Superior de Juiz de Fora, Licenciada em Pedagogia pela Universidade Federal de Juiz de Fora e Bacharel em Psicologia pelo Centro de Ensino Superior de Juiz de Fora. Atua como Professora Titular da Faculdade de Educação da Universidade Federal de Juiz de Fora, onde compõe o quadro docente do Programa de Pós-Graduação em Educação e integra o Grupo Tempos do Núcleo de Estudos e Pesquisas em Educação e Diversidade (NEPED). E-mail: luciana.marques65@gmail.com
} 


\title{
MEMORIES, KNOWLEDGE AND DREAMS IN THE CONTINUED FORMATION OF COUNTRYSIDE TEACHERS.
}

\begin{abstract}
This text brings up reflections and questions developed from a collaborative research proposal on teachers' autobiographic narratives that work in the countryside which present us elements about teaching, whether in the form how we exercise it or whether in how we describe it by means of memories from childhood or from school. Thus, focusing on these teachers' life stories, we survey the possible dynamics of the construction of knowledge in this context, whose scenario is the Municipal School of Santa Bárbara, at Miradouro town, MG. We quote authors such as Paulo Freire, Michel de Certeau e Boaventura de Souza Santos to dialogue with these teachers' speeches filled of memories, knowledges and dreams.
\end{abstract}

Keywords: Memories - Knowledge Building - Teacher Training.

A caminhada afirma, lança, suspeita, arrisca, transgride, respeita etc., as trajetórias que falam. Todas as modalidades entram ai em jogo, mudando a cada passo, e repartidas em proporções, em sucessos, e com intensidades que variam conforme momentos, os percursos, os caminhantes MICHEL DE CERTEAU, 1994).

\section{Introdução}

A experiência que iremos compartilhar baseia-se numa proposta de pesquisa colaborativa na qual nos propusemos a refletir a partir das narrativas de professoras acerca dos processos formativos, da produção de conhecimentos e dos elementos sobre a docência, de uma forma geral, no que tange como a exercemos e como a pensamos, através das lembranças da infância e da escola.

A Escola Municipal de Santa Bárbara, escolhida como lócus da pesquisa, é uma das 7 escolas situadas em comunidades rurais do município de Miradouro/MG, cuja rede municipal de ensino conta com 12 escolas. Este município localiza-se na porção norte da zona da mata mineira e que, de acordo com o censo demográfico de 2010, tem uma população aproximada de 10 mil habitantes, majoritariamente aglomerados em pequenos povoados nos quais as principais atividades rentáveis são a agricultura e a pecuária, destacando-se a cultura do café.

A proposta de pesquisa foi construída com a participação dos pesquisadores e 14 profissionais da escola. Estes todos do sexo feminino, com idades entre 24 e 52 anos, predominantemente nascidas e criadas em Miradouro. Exceto por uma monitora de atividades complementares do horário integral da escola, as outras 
têm formação específica para o exercício docente, sendo duas formadas no Magistério, uma no Normal Superior, uma em Física e as demais em Pedagogia.

Em um processo de aproximação/diálogo foi se configurando o nosso objetivo/desejo em comum: o registro e a reflexão acerca da escolha das práticas pedagógicas forjadas no processo de construção da educação do campo no município e dos motivos que nos levam a elas. 0 desejo comum era a construção de um percurso investigativo que, além de construir conhecimentos acadêmicos, pudesse vitalizar o processo político-pedagógico vivenciado neste contexto escolar. Neste artigo trazemos um dos momentos desta caminhada, algumas reflexões a partir da nossa primeira Roda de Conversas. Quem eram as professoras? Estariam então, suas expectativas e sonhos em consonância com as expectativas e sonhos de seus alunos? Que lembranças guardam de suas vivências escolares? Onde estão estas lembranças, estão latentes ou ocultadas pela estrutura de poder a que pertencem? 0 que pensam as professoras que trabalham na "roça" sobre a "roça"?

\section{A experiência partilhada}

Pensar sobre como se forma o professor é sempre um caminho de muitas encruzilhadas... Há aqueles que sempre sonharam com a docência e que relatam as "brincadeiras de escolinha" desde a infância, há também aqueles que não a desejavam, mas que, por motivos variados, foram levados a ela e acabaram descobrindo que o exercício de ser professor os completava. Cremos que entre um polo e outro há tantas outras possibilidades de chegada ao magistério que não nos

é possível descrever. Isso porque estamos apenas focando nas situações em que há uma relação de satisfação com a docência e, se olharmos também para aquelas nos quais, por opção ou por falta desta, a docência é exercida, mas sem nenhuma satisfação ou sonho, as possibilidades se multiplicam.

Neste contexto, partimos do pressuposto de que há inúmeras formas de se chegar à docência, mas a capacidade de sonhar é o que distingue a forma como ela será efetivada. A docência é eminentemente um lugar de conhecimentos e, portanto, de construir expectativas, de sonhar. Educar é acreditar num projeto, é ter metas para si e para o outro. Não se educa sem sonho, sonho que sempre envolve o outro. E não se é educado sem que se envolva no sonho de alguém...

O conhecimento [...] exige uma presença curiosa do sujeito em face do mundo. Requer sua ação transformadora sobre a realidade. Demanda uma busca constante. Implica em invenção e em reinvenção. Reclama reflexão crítica de cada um sobre o ato mesmo de conhecer, pelo qual se reconhece conhecendo e, ao reconhecer-se 
assim, percebe o "como" de seu conhecer e os condicionamentos a que está submetido seu ato (FREIRE, 1983, p. 27).

Não há como investir em algo que não se acredita, não investir por inteiro, então, são nossas expectativas que se fazem presentes naquilo que desejamos aprender/ensinar. E ter a clareza de quais são nossos sonhos, ou seja, do que nos move enquanto sujeitos, dos conhecimentos que consideramos importantes e quais não consideramos é a base da reflexão sobre a forma como exercemos a docência.

Nós, professores e professoras, somos um dos poucos, senão os únicos profissionais, que chegam ao seu lugar de trabalho, à escola, já tendo passado pelo menos dezesseis anos imersos nela e isso nos marca. Todos têm uma memória da escola, mas, para os profissionais da educação, esta memória assume contornos de conhecimentos prévios e cada um de nós tem razões insuspeitas para retornar e permanecer neste lugar. Assim, trazer à tona as memórias do "tempo de escola", para nós professores, é mais do que simples reminiscência, é pensar os saberes e fazeres da docência, tanto os que vivenciamos enquanto alunos quanto os que vivenciamos como professores. Que lembranças guardamos e quais perdemos nesse retorno à escola? Como estas marcas que a escola nos deixou se refletem em nossos sonhos e nas nossas expectativas em relação à docência?

Entendemos, que a memória é uma construção de fragmentos representativos do passado: para Halbwachs (2004), por exemplo, toda memória é coletiva e se constitui um elemento essencial da identidade, da percepção de si e dos outros. Não lembramos de tudo que vivenciamos, mas guardamos aquilo que nos foi significativo e ao trazermos à tona, pode-se dizer que filtramos nossas lembranças, ativando aquilo que queremos, que nos é significativo. Segundo Matos e Senna (2011), não podemos impedir que certas lembranças aflorem, mas controlamos o que dessas lembranças sairão da esfera do íntimo, do privado, e ganharão vida própria no público.

Ativar lembranças e, mais do que isso, torná-las públicas requer uma aproximação, uma certa intimidade. E, para alcançar isso, é preciso que os participantes se respeitem, seja em uma roda de conversa ou em uma entrevista, pois o resultado depende da relação de amizade conquistada através do processo de aproximação e de construção das condições para a realização da pesquisa colaborativa, que pressupõe uma certa cumplicidade e a confluência de objetivos comuns entre nós - pesquisadores ligados à universidade e a escola. Durante este contato, foi-se construindo uma interação entre as equipes nas várias visitas e participações em reuniões e encontros de gestores e docentes. 


\section{A produção do conhecimento: verdades possíveis}

Esta experiência de investigação nos possibilitou o contato com diferentes lembranças acerca da escola. As histórias contadas nas rodas de conversa nos mostraram que todas nós trazemos de nosso cotidiano escolar lembranças, imagens, vozes, leituras, manifestações de afeto ou de desafeto que nos remetem a um momento específico da vida presente ou passada: as lembranças boas, que nos fizeram felizes, nos fizeram rir e as não tão boas assim.

O lugar que a escola ocupou e ocupa em nossas vidas nos faz reconhecer que a escola, de uma forma ou de outra, nos marca e as marcas que ela deixa em nós podem, em certa medida, dizer muito de quem somos. Mas, como nos diz Freire (2000, p. 75), “a questão fundamental não está em que o passado passe ou não passe, mas na maneira crítica, desperta, com que entendemos a presença do passado em procedimentos do presente".

As evidências de que o que aprendemos na escola foi muito além daquilo que estava previsto nos currículos prescritos ou nos planejamentos daqueles que foram nossos professores e professoras, nos possibilitam "(re)pensar" nossa prática pedagógica. Nossas memórias de escola nos mostraram que muitos saberes que precedem e tantas vezes guiam, de forma insuspeita, nossas práticas, não estavam previstos, mas os colocamos em prática mesmo assim.

Nossas lembranças nos desestabilizam e nos fazem olhar de outro jeito para o que acontece todo dia e, de repente, perceber que havia algo ali, não visto anteriormente, é olhar para o mesmo e ver o diferente. E esta nova perspectiva pode ser o ponto de partida para construirmos a escola que sai da escola e se encontra com a vida. Enquanto restrita a si mesma, a escola faz pouco sentido, mas, quando inserida na vida de cada sujeito, ela é potencialmente revolucionária, ela muda a sociedade, não em um futuro, mas hoje, agora. "Se a educação sozinha não transforma a sociedade, sem ela tampouco a sociedade muda" (FREIRE, 2000, p. 67).

Minuciar reflexões sobre a docência (como a exercemos e como a pensamos através das lembranças escolares) traz a narrativa para um lugar central e denota a compreensão que temos de que o foco do conhecimento é o humano e suas ações. A perspectiva das histórias de vida muda o eixo do conhecimento, que deixa de focar nas coisas, para conhecer quem conhece as coisas, ou seja, as pessoas. Esse é um fundamento, conhecer as pessoas: tanto os outros, numa perspectiva de alteridade, quanto a nós mesmos. Como nos diz Santos (2006a), todo o conhecimento é autoconhecimento. 
De certo modo, a aluna que fomos não ecoa na professora que somos? 0 que fomos sempre ecoa em nós, por mais distantes que estejamos dos muitos espaços e tempos que habitamos. Eles nos configuram, seja por contraste ou por afirmação.

$\mathrm{Na}$ crise dos fundamentos e diante do desafio da complexidade do real, todo conhecimento hoje necessita refletir sobre si mesmo, reconhecer-se, situar-se, problematizar-se. A necessidade legítima de todo cognoscente, doravante, seja quem for e onde estiver, deveria ser: não há conhecimento sem conhecimento do conhecimento (MORIN, 1999, p. 34).

Parece contraditório, mas realmente é fato que, no meio acadêmico, construir conhecimentos a partir de lembranças, apesar de terem importância singular na formação do sujeito, é algo que ainda sofre preconceitos e pelo qual precisamos reivindicar o reconhecimento.

Ao assumirmos as narrativas autobiográficas e memórias como processos de produção de conhecimento, está subjacente nossa concepção de que o conhecimento produzido é uma das verdades possíveis. Esta assunção nos leva a uma outra constatação, a qual toda reflexão pressupõe um posicionamento, uma consideração a partir de um lugar e o lugar de onde se fala, seja este explicitado ou não, interfere na forma e no conteúdo a ser estudado. 0 fato é que tanto o foco do estudo quanto os pesquisadores estão situados no tempo e no espaço, imersos em relações sociais, o que pode influenciar as reflexões a serem feitas.

Uma das falácias do pensamento moderno foi a tentativa de convencimento de que o mundo que a ciência inventa é o real. Essa pseudoconcretude e invariabilidade foram produzidas discursivamente e, mesmo sendo o tempo todo revista, reescrita e apagada, ainda é uma prerrogativa que uma determinada perspectiva de ciência continua tentando produzir: um discurso sobre $o$ real. Assumimos a provocação do poeta Manoel de Barros (2003, p. 61) que diz que "Tudo o que não invento é falso" e, segundo Santos (2006a), o paradigma da ciência moderna está em crise e as condições sociais proporcionadas por essa crise são favoráveis à construção de um novo paradigma emergente, que não pode ser apenas científico, precisará ser também social, por isso o denomina "paradigma de um conhecimento prudente para uma vida decente".

Para isso é necessária uma outra forma de conhecimento, um conhecimento compreensivo e íntimo que não nos separe e antes nos una pessoalmente ao que estudamos e que nossas trajetórias de vida pessoais, nossos valores e crenças são parte do que conhecemos ou podemos conhecer (SANTOS, 2006a, p. 85).

Um conhecimento compreensivo e íntimo requer formas e métodos compreensivos e íntimos. Mas, como observa Certeau e Giard (2005, p. 341-342), 
[...] conhecemos mal os tipos de operações em jogo nas práticas ordinárias, seus registros e suas combinações porque nossos instrumentos de análise [...] foram constituídos para outros objetos e com outros objetivos [...]. Nossas categorias de saber ainda são muito rústicas e nossos modelos de análise por demais elaborados para permitir-nos imaginar a incrível abundância inventiva das práticas cotidianas.

Para Certeau (1994), ao falarmos ou ao narrarmos, estamos praticando uma arte e essa produz efeitos. Assim, o narrar não seria um retorno à descrição, mas um ato que procura provocá-la, distanciando-se cautelosamente da realidade.

\section{Memórias, saberes e sonhos}

Procurando incitar a produção da arte de narrar, planejamos, juntamente com as professoras da escola Santa Bárbara, um encontro para conversar sobre as nossas vidas, de nossas experiências escolares até nossa trajetória profissional. Era um desafio enorme. Decidimos trazer para a roda de conversas uma brincadeira quase infantil. Propusemos a construção de um rio, o rio das nossas vidas.

Para isso, iniciamos colocando papéis e materiais de desenho no meio da roda enquanto falávamos para o grupo que imaginassem sua vida como se fosse um rio. Tem uma nascente e segue um curso que ora está turbulento ora mais tranquilo, estreito, enfim. Então, todas deveriam colocar o seu nome, a cidade onde nasceram e a data de nascimento na nascente do rio e também deveriam escolher partes do rio para representar (através de símbolos, desenhos, frases) momentos significativos de sua vida no ambiente escolar. Todo processo foi gravado em vídeo e transcrito para produção de documentos.

A escola nos recebeu com carinho e muita expectativa e o ambiente descontraído e de integração entre todos possibilitou o envolvimento na atividade e a descoberta de histórias destas mulheres que sempre estiveram ligadas ao campo. 0 sentimento de pertencimento a esse território cheio de significados foi o marco comum nos diferentes relatos de vida, bem como o orgulho da identidade de ser hoje uma professora de escola do campo. Para aquele momento cada trajetória foi longa, mas, assim como o caminho do rio utilizado na dinâmica motivadora, foi, em diferentes momentos, sinuosa, com pedras, quedas e percalços, mas também calma e tranquila.

Como protagonistas das suas histórias, apresentaram diferentes caminhos trilhados que culminaram na escola do campo que estão construindo: surgiram memórias da infância e da escola, carregadas de significados que permanecem vivos e influenciaram atitudes e decisões, inclusive a de tornar-se professora. 
Tive uma professora que me marcou muito... que talvez fez eu ter esse sonho de ser professora um dia (FERREIRA, 2015).

Meu primeiro marco foi a minha professora de primeira série. Graças a Deus ela tá viva. Eu acho ela uma gata, muito bonita, bacana. Eu pus ali um marco, e uma estrela, porque ela é minha estrela. Desde quando eu estudei com ela eu decidi que eu seria professora. É a Raquel, do Joaquim. Tem coisas, passagens, que eu lembro como uma brincadeira da cadeira. A gente fez um festival da escola e na brincadeira da cadeira eu ganhei, eu sempre fui, apesar de hoje não ser, era muito magrinha... Eu era mais magrinha do que ela, e eu ganhei na dança da cadeira e eu lembro que ela chegou assim, me pegou no colo, me abraçou, me jogou pra cima sabe?! São coisas que ficaram marcadas, e quando eu passei pra segunda série, ela foi na fila e falou com a minha professora, da segunda série, cê cuida dessa menina tá? Que ela vai longe... (VALENTE, 2015).

Algumas tiveram a experiência de estudar em escola urbana quando crianças, mesmo morando no campo, e enfrentaram as dificuldades inerentes à escassez e ao abandono ao qual eram relegadas as comunidades rurais.

Em Miradouro era difícil para estudar. De primeira a quarta série não tanto porque tinham as escolas rurais. A Rosilene, sabe, foi minha professora, tinha que andar de bicicleta, não tinha carro, depois fui morar com minha avó bem distante, eu queria muito estudar, mas as pessoas falavam: se eu fosse você não faria isso, são muitas barreiras, mas eu consegui. Ingressei na faculdade formei em Pedagogia e hoje é uma realização estar trabalhando como professora (ALVES, 2015).

Apesar dos desafios, ir para a escola era um momento de reencontro, de diversão, uma vez que o trabalho era comum desde a infância e muitas vezes os amiguinhos moravam distantes, portanto, a escola, fora de sua característica formal e sua disciplina tão rígida na época, significava para as crianças o "ser criança". 0 longo trajeto de casa à escola era marcado de doces momentos de brincadeiras e aventuras. A hora do recreio era um vento de alegria que soprava nos rostinhos que corriam para brincar. "Era muito longe. Mas eu tinha aquele prazer de ir pra escola, encontrar com os colegas e brincar" (DORES, 2015).

Outras histórias elucidaram as limitações de se iniciar a carreira nas escolas do campo de outros tempos - e em alguns locais ainda hoje - onde uma ou duas professoras desempenhavam todos os papéis na escola.

Eu e minha amiga Dorinha começamos juntas lá na Serrania. Quando eu cheguei lá, era uma dificuldade enorme, muito distante. Como eu ia trabalhar? Como eu ia começar? Não tem tudo isso que temos hoje. (...) Diretora era eu e a Dorinha era minha supervisora e eu era supervisora dela. As turmas eram multisseriadas. Eu dava aula pro pré, primeiro e segundo. Dorinha pegava o terceiro, o quarto e o quinto. Então a gente tinha que trocar entre a gente e não tinha essa troca boa que temos hoje (MELLO, 2015). 
Entretanto, mesmo em meio a tantos desafios, essas professoras resistiram e relatam o quanto o trabalho em equipe as motivou para continuar, realizar, superar e sonhar.

Então quando eu cheguei aqui eu vi meu desafio. Qual é meu desafio?! É estudar... (risos). Estudar! Mas não é porque eu preciso do diploma não! Não é que eu sei muuuito não! Mas eu aprendi muito! Eu aprendi láá com as pedras até eu chegar aqui! Passei por outras escolas, eu já cheguei aqui, onde eu fui bem-vinda... Primeiro ano que eu trabalho aqui... Me apoiam, o supervisor me apoia, minha diretora faz tudo que pode também! (MELLO, 2015).

No terceiro eu coloquei essa realização de sala de aula, porque com a equipe que a gente tem aqui, graças a Deus dá pra fazer um trabalho bom, porque a gente precisa de ajuda, sempre tem alguém pra apoiar. E quando a gente melhora a gente vê o resultado né? Por que se você faz um trabalho, a Luceni mostra pra todo mundo. Às vezes nem fala com a gente, mas só dela tá mostrando pra outra pessoa, você sente que você... Fez né? Certo, que você tá no caminho certo (FREITAS, 2015).

As palavras de reconhecimento da professora Valquíria para com sua colega Rosilene, que a incentivou a estudar e também a fazer outras atividades na escola, mostram um saber indispensável ao trabalho docente: incentivo, companheirismo, demonstrações de amor e afeto, enfim, a humanização das relações. Veja: "Eu acho que você me ensinou a fazer... Você me colocou assim 'Você sabe fazer, eu confio em você, você vai fazer...' Porque assim eu sei que eu sei fazer..." (MELLO, 2015).

Experiência semelhante foi compartilhada pela professora Fabiana: a importância do apoio e do auxílio no momento inicial da carreira do magistério, que é marcado pelos medos, inseguranças, mas também por expectativas e sonhos de que as suas ações enquanto professora poderiam marcar positiva ou negativamente a vida de muitas crianças. Veja: “[...] só que eu tive muita ajuda. Teve muitas pessoas importantes, que me ajudaram muito... Alguns estão aqui... Aliás, todas elas hoje fazem parte da minha vida agora né?!” (PEREIRA, 2015).

Para essas professoras, há um significado especial na escolha da docência como profissão. Um sentido de valorização, de pertencimento, de mudança na vida de outrem, de realização.

O trabalho, eu coloquei a palavra trabalho, porque através do trabalho, é... com ele eu estou realizando sonhos pra minha vida né? (DORES, 2015).

O que eu gosto realmente é de ser professora. Faço com amor, com prazer, é lógico que a gente erra, têm falhas, né? Nem tudo sai perfeito, mas eu tento fazer o melhor possível (FREITAS, 2015). 
As experiências das rodas criaram um ambiente intenso de diálogo, inclusive para extravasar descontentamentos, frustrações, indignações, além de anseios e projetos de futuro, pessoais e profissionais, como construir novos saberes junto com as pessoas valorizando o conhecimento que cada uma trazia consigo.

\footnotetext{
Sabedoria, plantar essa semente... eu volto muito para o conhecimento. Eu tenho lido muito e tenho conversado com muitas pessoas antigas, pessoas mais velhas aqui da comunidade, que quando a gente fala em sabedoria, a quantidade de coisas boas que esse povo tem pra passar pra gente. Desde aquele matuto lá da roça até um profissional, uma supervisora de escola. Então cê pode comparar, o que você aprende com o matuto é tão importante do que quando eu aprendo com a Roseli aqui na escola. Então essa sabedoria aí é uma coisa que eu tenho aprendido com o povo, com as companheiras de trabalho (OLIVEIRA, 2015).
}

Estes são alguns fios que trouxemos para que se formem os tecidos da rede de interações que enriquecem a identidade da escola e fortalecem os laços de confiança e amizade entre as professoras. As memórias e os conhecimentos construídos ao longo de uma jornada são ressignificados, beneficiados e ampliados com as trocas.

\section{Tecendo conclusões e reflexões: os aprendizados possíveis}

O caso aqui descrito permitiu uma profunda reflexão sobre os processos escolares que marcaram a vida das professoras, os quais permitiram que elas se tornassem as pessoas e profissionais que são hoje, com desejos de um mundo melhor.

Eu quero muito que o mundo seja um lugar melhor, que as pessoas respeitem umas às outras e tratem melhor umas às outras, com amor. Que assim a gente vai ter um mundo melhor, com menos violência, menos guerra. E pra ter um mundo melhor a gente tem que começar primeiro... Dentro da escola! (JOÃO, 2015).

A reflexão decorrente da atividade forneceu subsídios para novos planejamentos e planos de ação para a escola, pois as histórias trouxeram à tona as memórias da escola e da educação rural de outrora, os erros que não devem ser repetidos e quais os desafios para a escola do campo dos dias atuais. Ao rememorar e refletir sobre práticas pedagógicas, as professoras destacaram a relevância de fazer da realidade das comunidades rurais uma fonte de trabalho, pesquisa e construção de conhecimento, tanto para elas quanto para os alunos. Num outro sentido, fortaleceu o vínculo entre o grupo, promoveu a identidade de ser professora de uma escola do campo e também denotou a importância do 
trabalho em equipe e a motivação pessoal para dar continuidade aos projetos individuais e coletivos.

Numa análise mais ampla, podemos dizer que, a partir destas experiências, estão sendo explicitados outros conhecimentos que foram marginalizados durante muito tempo, considerados insignificantes numa sociedade urbana e industrial. Ao dar visibilidade a vozes que foram silenciadas, um paradigma histórico está sendo redesenhado, os saberes do campo e, em especial, das professoras, que também são sujeitos desse espaço, estão aparecendo e podem configurar uma nova maneira de ver esses sujeitos e esse cenário.

As histórias contadas podem parecer muito simples, pequenas coisas que foram compartilhadas nas rodas, pequenos fragmentos da complexidade que são nossas histórias de vida, mas nos permitem perceber as dinâmicas que as possibilitaram e a forma como foram enredadas. Esses pequenos acontecimentos que, como táticas, podem ter sido resultado do imprevisível, do incontrolável, do diverso, do singular e, como tal, podem não tornar a acontecer da mesma forma, podem, entretanto, atribuir sentidos às experiências compartilhadas, criando possibilidades de modificar as nossas redes de conhecimentos. Como nos diz Giard (2005, p. 220, grifos nossos), é preciso

[...] aceitar, como dignas de interesse, de análise, de registro, estas práticas comuns tidas como insignificantes. Aprender a olhar estas maneiras de fazer, fugitivas e modestas, que são frequentemente o único lugar possível de inventividade do sujeito: invenções precárias sem nada que as consolide, sem língua que as articule, sem reconhecimento que as eleve; misturas submetidas ao peso das dificuldades econômicas, inscritas na rede das determinações concretas.

E o espaço de socializar estas "maneiras de fazer, fugitivas e modestas" é aquele que se constrói na interação, na conversa, nos registros e nas reflexões e discussões destes. Isso forma professoras! Pelo menos as que serão capazes de criar e recriar suas próprias teorias e práticas.

O conhecimento [...] exige uma presença curiosa do sujeito em face do mundo. Requer sua ação transformadora sobre a realidade. Demanda uma busca constante. Implica em invenção e em reinvenção. Reclama reflexão crítica de cada um sobre o ato mesmo de conhecer, pelo qual se reconhece conhecendo e, ao reconhecer-se assim, percebe o "como" de seu conhecer e os condicionamentos a que está submetido seu ato (FREIRE, 1983, p. 27).

Por outro lado, a experiência de estarmos juntos numa roda de professoras, compartilhando experiências e saberes, nos fez perceber que não há como investir em algo que não acreditamos, investir sem estarmos inteiros, sem o sonho que nos move. A ecologia de saberes se assenta na pluralidade de saberes 
heterogêneos, da autonomia de cada um deles e da articulação sistêmica, dinâmica e horizontal entre eles.

$\mathrm{Na}$ ecologia de saberes cruzam-se conhecimentos e, portanto, também ignorâncias. Como não há ignorância em geral, as ignorâncias são tão heterogéneas, autónomas e interdependentes quanto os saberes. Dada esta interdependência, a aprendizagem de certos conhecimentos pode envolver o esquecimento e a ocultação de outros e, em última instância, a ignorância destes (SANTOS, 2006b, p. 157).

A experiência da roda de conversas trouxe mais uma ferramenta de capacitação ao grupo de professoras, visto que conseguiram articular as diferentes histórias que convergiram num ponto comum: que educação se pretende para os sujeitos que vivem no campo, sua escola, benefícios e dificuldades de viver ali. E, permeada pela subjetividade e emoção vivida por cada professora, este exercício criou um ambiente de respeito mútuo e de busca coletiva de soluções e forças para seguir trabalhando no que se acredita, no sonho de cada uma e nos sonhos que sonham juntas.

\section{Referências}

ALVES, Flávia Maria Machado. Roda de conversa [24, out., 2014]. Coordenador da Roda de Conversas: Douglas Tomácio Lopes Monteiro. Arquivo audiovisual do projeto "A educação básica do campo na escola pública e a participação dos movimentos sociais do campo nas práticas escolares e não escolares na cidade de Miradouro" - MG. UFJF, 2015.

BARROS, Manoel de. Livro sobre nada. 4. ed. Rio de Janeiro: Record, 2003.

CERTEAU, Michel de. A invenção do cotidiano - Artes de fazer. Petrópolis, RJ: Vozes, 1994.

CERTEAU, Michel de e GIARD, Luce. Uma Ciência Prática do Singular. IN: CERTEAU, Michel de; GIARD, Luce; MAYOL, Pierre. A invenção do cotidiano: 2. morar, cozinhar. 8. ed. Petrópolis: Vozes, 2005. p. 335-343.

DORES, Maria das. Roda de conversa [24, out., 2014]. Coordenador da Roda de Conversas: Douglas Tomácio Lopes Monteiro. Arquivo audiovisual do projeto "A educação básica do campo na escola pública e a participação dos movimentos sociais do campo nas práticas escolares e não escolares na cidade de Miradouro" - MG. UFJF, 2015.

FREIRE, Madalena. A paixão de conhecer o mundo: relato de uma professora. Rio de Janeiro: Paz e Terra, 1983. 
FREIRE, Paulo. Pedagogia da indignação: cartas pedagógicas e outros escritos. São Paulo: Editora UNESP, 2000.

FERREIRA, Elisiane Aparecida de Oliveira. Roda de conversa [24, out., 2014]. Coordenador da Roda de Conversas: Douglas Tomácio Lopes Monteiro. Arquivo audiovisual do projeto "A educação básica do campo na escola pública e a participação dos movimentos sociais do campo nas práticas escolares e não escolares na cidade de Miradouro" - MG. UFJF, 2015.

FREITAS, Eva Maria da Conceição. Roda de conversa [24, out., 2014]. Coordenador da Roda de Conversas: Douglas Tomácio Lopes Monteiro. Arquivo audiovisual do projeto "A educação básica do campo na escola pública e a participação dos movimentos sociais do campo nas práticas escolares e não escolares na cidade de Miradouro" - MG. UFJF, 2015.

GIARD, Luce. Artes de Nutrir. IN: CERTEAU, Michel de; GIARD, Luce; MAYOL, Pierre. A invenção do cotidiano: 2. morar, cozinhar. 8. ed. Petrópolis: Vozes, 2005. p. 211-234.

HALBWACHS, Maurice. A memória coletiva. São Paulo: Centauro, 2004.

JOÃO, Maria. Roda de conversa [24, out., 2014]. Coordenador da Roda de Conversas: Douglas Tomácio Lopes Monteiro. Arquivo audiovisual do projeto "A educação básica do campo na escola pública e a participação dos movimentos sociais do campo nas práticas escolares e não escolares na cidade de Miradouro" - MG. UFJF, 2015.

MATOS, Júlia Silveira; SENNA, Adriana Kivanski de. História Oral como fonte: problemas e métodos. Historiae, Rio Grande, v. 2, n. 1, p. 95-108, 2011.

MELLO, Walkíria Vita de. Roda de conversa [24, out., 2014]. Coordenador da Roda de Conversas: Douglas Tomácio Lopes Monteiro. Arquivo audiovisual do projeto "A educação básica do campo na escola pública e a participação dos movimentos sociais do campo nas práticas escolares e não escolares na cidade de Miradouro" - MG. UFJF, 2015.

MORIN, Edgar. 0 método 3: a consciência da consciência. 2. ed. Porto Alegre: Sulina, 1999.

OLIVEIRA, Luceny Ribeiro de Freitas. Roda de conversa [24, out., 2014]. Coordenador da Roda de Conversas: Douglas Tomácio Lopes Monteiro. Arquivo audiovisual do projeto "A educação básica do campo na escola pública e a 
participação dos movimentos sociais do campo nas práticas escolares e não escolares na cidade de Miradouro" - MG. UFJF, 2015.

PEREIRA, Fabiana de Oliveira Campos. Roda de conversa [24, out., 2014]. Coordenador da Roda de Conversas: Douglas Tomácio Lopes Monteiro. Arquivo audiovisual do projeto "A educação básica do campo na escola pública e a participação dos movimentos sociais do campo nas práticas escolares e não escolares na cidade de Miradouro" - MG. UFJF, 2015.

SANTOS, Boaventura de Souza. Um discurso sobre as ciências. 4. ed. São Paulo: Cortez, 2006a. 2006b.

Gramática do tempo: para uma nova cultura política. São Paulo: Cortez,

VALENTE, Rosilene Aparecida. Roda de conversa [24, out., 2014]. Coordenador da Roda de Conversas: Douglas Tomácio Lopes Monteiro. Arquivo audiovisual do projeto "A educação básica do campo na escola pública e a participação dos movimentos sociais do campo nas práticas escolares e não escolares na cidade de Miradouro" - MG. UFJF, 2015.

Recebido em: 18/08/2017

Aprovado em: 10/09/2017 